Silencing Huntington's gene

A molecule that lowers the expression of the mutant protein that causes Huntington's disease reverses symptoms of the disorder in mouse models of the disease.

Don Cleveland at the University of California, San Diego, and his team infused a short string of nucleotides that blocks the expression of the huntingtin gene into the brains of mice bearing the disease-causing mutation. The molecule persisted in brain tissue for more than three months, and levels of mutant protein were reduced for up to four months after the infusion. Nine months posttreatment, the mice continued to show decreased anxiety and improved motor function.

When the oligonucleotide was infused into the cerebrospinal fluid of Rhesus macaques, levels of huntingtin messenger RNA fell in multiple brain regions. Neuron 74, 1031-1044 (2012)

\section{BIOPHYSICS}

\section{How cells} \section{maintain chains}

Long protein chains in the form of microtubules and actin filaments give cells their shape and rigidity, and also perform chores such as yanking apart copies of chromosomes. Two mathematical models explain how the length of these chains is kept in check by molecular motor-proteins that 'walk' along the chains.

Karsten Kruse and his team at Saarland University in Saarbrücken, Germany, modelled the growth and shrinkage of actin filaments, which occurs at both ends of the chain. Erwin Frey and his group at the Ludwig Maximilian University in Munich, Germany, focused on microtubules, which are trimmed by molecular motors at a single tip.

The teams found that molecular motors control chain length by forming 'traffic jams' at specific places along the chain. At these spots, protein building blocks are continuously gained and shed so that the overall length remains stable. The location of the traffic jam determines the length of the chain, which terminates at the jam.

Phys. Rev. Lett. 108, 258103; 258104 (2012)

\section{NEUROSCIENCE}

\section{DNA methylation controls memory}

As animals age, the addition of methyl groups to DNA - a mechanism that controls gene expression - decreases in the brain. This reduction causes cognitive decline, researchers now show.

Hilmar Bading and his colleagues at the University of Heidelberg in Germany showed that a gene central to DNA methylation, Dnmt3a2, controls cognitive abilities in mice. When the researchers overexpressed Dnmt3a2 in the hippocampal brain area of elderly mice, the animals regained their cognitive skills in two long-term-memory tests. Reducing hippocampal expression of the gene caused young adult mice to perform poorly in the tests compared with controls of the same age. Nature Neurosci. http://dx.doi. org/10.1038/nn.3151 (2012)

\section{CLIMATE CHANGE}

\section{Lopsided warming north to south}

The Northern Hemisphere is warming more quickly than the Southern Hemisphere thanks to the uneven distribution of land and sea around the globe, a study confirms.

Land masses warm more quickly than the ocean in part because more heat is required to raise the temperature of water than that of land, and in part owing to the cooling effects of sea surface evaporation. Yangyang Xu and

COMMUNITY CHOICE

The most viewed papers in science ECOLOGY

\title{
Illuminating invertebrate habitats
}

\section{HIGHLY READ \\ on rsbl.royalsociety- publishing.org in May}

Street lamps can shape the surrounding invertebrate community, attracting predators and scavengers day and night.

Thomas Davies and his team at the University of Exeter in Penryn, UK, set traps under and between 14 lamp posts on a street in a town in Cornwall, and collected samples before each sunrise and sunset for three days. The researchers classified the invertebrates on the basis of their feeding strategies: predators, scavengers, grazers, parasites and detritivores, which consume rotting material. Overall, there were more invertebrates under the lamps than between them, but predators and scavengers in particular were more abundant. Harvestmen, ants and ground beetles preferred the grass under the lamp posts both day and night, indicating that they were not simply drawn by the light.

Light pollution could affect the structure and function of ecosystems, the researchers suggest. Biol. Lett. http://dx.doi.org/10.1098/ rsbl.2012.0216 (2012)

Veerabhadran Ramanathan of the Scripps Institution of Oceanography in La Jolla, California, used climate simulations to confirm that these effects can explain the global pattern of temperature change seen during periods of warming - in 1910-40 and 1975-2005 - as well as during a cooling period in 1940-75. The climate-model runs predict drastic changes in rainfall, including intense droughts in Africa, Western North America, the Amazon and Australia, and a boost to the Indian monsoon.

Geophys. Res. Lett. http://dx.doi. org/10.1029/2012GL052116 (2012)

\section{NEUROSCIENCE \\ Gene blocks effects of stress}

Chronic stress can contribute to depression, but its effects can be blocked in rats by upregulating a single gene in one brain region.

A gene called neuritin encodes a protein that is involved in the growth of

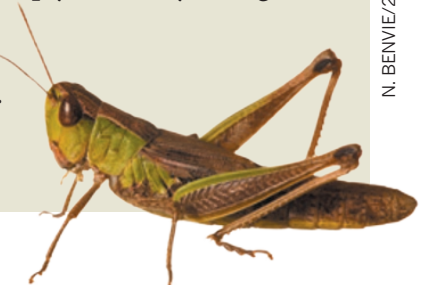

neuronal branches. Hyeon Son and Ronald Duman at Yale University in New Haven, Connecticut, and their team studied the gene at work in a rat model of chronic stress. The researchers found that exposure to stress decreased neuritin expression in a region of the brain called the hippocampus, and that the effect was reversed by an antidepressant. Boosting neuritin protein levels increased the amount of neuronal branching and prevented stress from affecting the animals' behaviour. Silencing the neuritin gene brought on depression-like behaviours.

Chronic stress leads to atrophy of hippocampal neurons, which can increase susceptibility to mood disorders, the authors suggest. Proc. Natl Acad. Sci. USA http://dx.doi.org/10.1073/ pnas.1201191109 (2012)

\section{$\rightarrow$ NATURE.COM}

For the latest research published by Naturevisit:

www.nature.com/latestresearch 